\title{
THE INTERRELATIONSHIPS OF THE CARDIOVASCULAR, RE- NAL AND ELECTROLYTE EFFECTS OF INTRAVENOUS DIGOXIN IN CONGESTIVE HEART FAILURE ${ }^{1}$
}

\author{
By LUDWIG W. EICHNA, SAUL J. FARBER, ADOLPH R. BERGER, DAVID P. \\ EARLE, BERTHA RADER,2 EDMUND PELLEGRINO, ROY E. ALBERT, ${ }^{3}$ \\ J. DEAVER ALEXANDER,² HARRY TAUBE, AND SOL \\ YOUNGWIRTH 2
}

\author{
(From the New York University College of Medicine and the Third [New York University] \\ Medical Division, Bellevue Hospital, New York, N. Y.)
}

(Submitted for publication June 27, 1951 ; accepted August 13, 1951)

Several studies have shown that rapid and marked improvement in cardiovascular dynamics results when the cardiac glycosides, digoxin (1-5), ouabain (6) and lanatoside $C(7)$ are administered intravenously to patients with congestive heart failure. At times the improvement is so marked that the altered functions are returned to the normal state. There remains the question whether concomitant improvement occurs in the circulation and function of the various organs. In this regard the kidney is of particular interest, not only because of its relationship to the development of some of the characteristic manifestations of congestive heart failure, but also because of the brisk diureses $(8,9)$ which the intravenously administered glycosides often induce.

The present study was designed to determine the interrelationships of the cardiovascular, renal and electrolyte effects of single therapeutic doses of digoxin administered intravenously to patients with congestive heart failure, and specifically to answer two questions : 1) Do renal hemodynamics improve concomitantly with the known improvement in cardiovascular dynamics? and 2) What is the relationship of the ensuing diureses to the general cardiovascular and renal hemodynamic effects?

\section{METHODS}

General. The plan of study was to make serial determinations of six categories of function known to be altered in congestive heart failure. Accordingly, cardiac output was measured by the direct Fick method, cardiac

1 This study was assisted by Grants in Aid from the New York Heart Association, Inc., and the Life Insurance Medical Research Fund.

2 Fellow, New York Heart Association, Inc.

3 Post-Doctorate Fellow, United States Public Health Service. and peripheral blood pressures by Hamilton manometers, oxygen content of blood by manometric analysis, blood volume by Evans blue dye (T 1824) method, renal hemodynamics by clearance techniques and electrolyte concentrations by flame photometer.

Patients. Five patients with congestive heart failure obtained therapeutic benefit from the intravenous digoxin and their data form the basis of this report. The congestive failure was considered severe in four patients and moderate in one. Two patients had hypertensive and arteriosclerotic heart disease, two had arteriosclerotic heart disease and one had rheumatic heart disease. All patients had auricular fibrillation. Edema was present in all five patients, respiratory distress at rest in four. Treatment before the study consisted of limited activity, bed rest in four, salt-poor diet in all patients and sedatives as required. Three patients had not received digitalis nor diuretics within the preceding month. Two patients, because of the severity of their clinical status, each received $0.5 \mathrm{mg}$. of digoxin intravenously several hours after hospitalization. One patient was studied 12 hours later, the other patient five days later. In both instances improvement had been minimal and the congestive failure was still severe at the time of the study. These small doses of digoxin were considered not to have altered the sequence of effects produced by the later therapeutic dose of the drug.

Procedures. Observations were made in the morning after an overnight fast. Electrodes for the electrocardiogram were applied and an indwelling catheter was placed in the urinary bladder. After appropriate priming doses, a sustaining infusion of inulin and para-aminohippurate (PAH) in distilled water was begun and delivered at a rate of $1 \mathrm{ml} . / \mathrm{min}$. by means of a pump. An intracardiac catheter, usually with a double lumen, was placed in the pulmonary artery or right heart (10) and perfused, at a rate of 3 to $4 \mathrm{ml} . / \mathrm{min}$., with $5 \%$ dextrose in water. The femoral artery and femoral vein were cannulated with indwelling Cournand needles, a respiratory tambour was placed about the chest and the patient was prepared for collection of expired air into a Tissot gasometer. For all local anesthesia a $2 \%$ solution of metycaine was used.

Determinations were made in 10 successive periods, each of 15 or 20 minutes duration. The plan of the determinations was to measure the cardiovascular hemody- 
namics (cardiac output, cardiac and peripheral blood pressures, blood oxygen contents and oxygen consumption) at the mid-point of the period during which the renal hemodynamics (glomerular filtration rate, renal plasma flow) and the water and electrolyte excretions were measured. Accordingly, the following procedures were carried out for each period: urine was collected at the end of the period and the bladder washed out with distilled water; over a three-minute interval, at the mid-point of the period, expired air was collected in the gasometer while arterial and right heart blood were collected during the last two of these three minutes; immediately following this sampling, arterial blood was obtained for inulin, $\mathrm{PAH}$, chloride, sodium, potassium and protein concentrations and for hematocrit; during the first 30 seconds of the expired air collection pressures in the femoral artery, right heart, and at times pulmonary artery and femoral vein, were recorded simultaneously by Hamilton manometers, together with the electrocardiogram and respiratory rate. Plasma volume was determined before, and again one and a half hours after, digoxin was given.

After three 15 -minute control periods, $1.0 \mathrm{mg}$. to 1.5 mg. of digoxin, diluted with $20 \mathrm{ml}$. to $30 \mathrm{ml}$. of $5 \%$ dextrose in water, was injected into a peripheral vein or the right atrium. The injection was made over an interval of 10 minutes, and 10 minutes later the period (fourth) was brought to a close. Then followed, in turn, three periods of 15 minutes each and three periods of 20 minutes each.

Analyses. Standard methods and procedures were used for the following analyses: oxygen and carbon dioxide in air (Haldane), oxygen and carbon dioxide in blood (11), plasma protein (12), blood and plasma volume (13), and the blood and urine concentrations of inulin $(14,15)$, PAH (16), chloride (17), and sodium and potassium (internal standard flame photometer). In blood, sodium was determined on serum and potassium on plasma, separated from heparinized blood within 15 minutes of sampling. Blood oxygen capacity at equilibrium with room air was determined on two samples; one pooled from periods 1,2 and 3 , the other from periods 8,9 and 10 . The hematocrit was measured in Wintrobe tubes. Heart rate was obtained from the electrocardiogram and ventilation volume from the expired air collection. For all pressure determinations the zero point of reference was 5.5 $\mathrm{cm}$. to $6.5 \mathrm{~cm}$. posterior to the angle of Louis. Systolic and diastolic pressures were obtained by averaging the respective pressures over two respiratory cycles and mean pressures by planimetric integration of the respective pressure waves over the same two respirations. Because of the edema and the acute nature of the observations, the values are presented without attempted correction for surface area.

\section{RESULTS}

Digoxin produced considerable subjective improvement in all five patients with congestive heart failure. A lessening of the general distress and anxiety, easier breathing and decreased orthopnea became apparent 20 to 30 minutes after the start of the injection. Improvement then continued for 30 to 45 minutes and some subjects even dozed a little. Thereafter, accumulating fatigue led to increasing discomfort and restlessness, but even so, the condition of the patients at the end of the observations was improved over that before the digoxin was given.

Changes in cardiovascular and renal functions and in urinary excretions occurred in all subjects and the averaged data for the five patients are presented in Table I and Figure 1. Since the averaged data obscure considerable differences in the action of the drug among the various patients, several important interrelationships for the individual patients are presented in a series of charts (Figures 2-6). The averaged data, nevertheless, indicate the more representative response and form the basis of the presentation.

Cardiovascular hemodynamic effects. The hemodynamic effects produced by digoxin were rapid in onset (Table $\mathrm{I}$ ). Thirty minutes after injection the drug's chief effects were fully evident, changing rapidly and consisted of : ventricular slowing, increased cardiac output, increased oxygen content of mixed venous blood, reduced $\mathrm{A}-\mathrm{V}$ oxygen difference, decreased peripheral venous pressure, decreased right atrial pressure, decreased right ventricular end diastolic pressure, decreased pulmonary artery diastolic pressure, increased peripheral arterial systolic and pulse pressures and a decrease in systemic vascular resistance. Over the ensuing one to one and a half hours these changes continued progressively but more slowly.

The first change usually observed was a slowing of ventricular rate, which became apparent five minutes after the start of injection of the drug and when only one-half of the dose had been given. At the time of the first hemodynamic measurements (five minutes after the end and 15 minutes after the start of injection) femoral venous and right atrial pressures had already fallen and systolic and diastolic arterial pressures had already risen. At this time cardiac output and $\mathrm{A}-\mathrm{V}$ oxygen difference showed inconsistent changes and pulmonary artery and right ventricular pressures remained unchanged. At the time of the next determinations (20 minutes after the end of injection) the 
TABLE I

The effect of intravenously administered digoxin on the cardiovascular, respiratory, renal and electrolyte functions in congestive heart failure*

(All data are averages for the number of patients indicated)

\begin{tabular}{|c|c|c|c|c|c|c|c|c|c|c|c|}
\hline \multirow[b]{2}{*}{ Period number } & \multirow{3}{*}{$\begin{array}{c}\text { Number } \\
\text { of } \\
\text { subjects } \\
\text { per } \\
\text { function }\end{array}$} & \multicolumn{3}{|c|}{ Before digoxin } & \multicolumn{7}{|c|}{ After start of injection of digoxin $\dagger$} \\
\hline & & 1 & 2 & 3 & 4 & 5 & 6 & 7 & 8 & 9 & 10 \\
\hline Time of period, minutes & & $\begin{array}{c}-50 \text { to } \\
-34\end{array}$ & $\begin{array}{c}-34 \text { to } \\
-18\end{array}$ & $\begin{array}{c}-18 \text { to } \\
0\end{array}$ & $\mathbf{0}$ to & $\begin{array}{c}22 \text { to } \\
38\end{array}$ & $\begin{array}{c}38 \text { to } \\
55\end{array}$ & 55 to & $\begin{array}{c}71 \text { to } \\
90\end{array}$ & $\begin{array}{l}90 \text { to } \\
108\end{array}$ & $\begin{array}{l}108 \text { to } \\
130\end{array}$ \\
\hline $\begin{array}{l}\text { Heart rate, per min. } \\
\text { Resp. rate, per min. }\end{array}$ & $\begin{array}{l}5 \\
5\end{array}$ & $\begin{array}{r}117 \\
28\end{array}$ & $\begin{array}{r}119 \\
28\end{array}$ & $\begin{array}{r}114 \\
29\end{array}$ & $\begin{array}{r}103 \\
29\end{array}$ & $\begin{array}{r}104 \\
28\end{array}$ & $\begin{array}{r}100 \\
28\end{array}$ & $\begin{array}{l}97 \\
28\end{array}$ & $\begin{array}{l}99 \\
27\end{array}$ & $\begin{array}{l}96 \\
28\end{array}$ & 97 \\
\hline
\end{tabular}

Expired Air

Ventilation volume, liters/min.

Oxygen consumption, $\mathrm{ml} . / \mathrm{min}$.

\begin{tabular}{|l|c|c|c|c|c|c|c|c|c}
\hline 10.76 & 10.68 & 10.40 & 11.19 & 11.02 & 9.74 & 10.15 & 10.03 & 9.64 & $=$ \\
250 & 267 & 249 & 257 & 251 & 251 & 251 & 233 & 233 & $=$ \\
\hline
\end{tabular}

Blood Gases

Arterial oxygen, vols. \%

Arterial oxygen saturation. $\%$

Mixed venous oxygen, vols. \%

Mixed venous oxygen saturation. \%

A-V oxygen difference, vols. \%

\begin{tabular}{|c|c|c|c|c|c|c|c|c|c}
\hline 16.6 & 16.6 & 16.6 & 16.3 & 15.9 & 15.7 & 15.6 & 15.6 & 15.5 & 15.5 \\
86 & 86 & 86 & 86 & 85 & 83 & 84 & 84 & 85 & 84 \\
8.8 & 8.6 & 8.4 & 8.3 & 9.4 & 9.7 & 9.8 & 9.9 & 9.1 & 9.2 \\
45 & 44 & 43 & 43 & 49 & 50 & 52 & 52 & 49 & 50 \\
7.8 & 8.0 & 8.2 & 8.0 & 6.5 & 6.0 & 5.8 & 5.7 & 6.4 & 6.3 \\
\hline
\end{tabular}

Blood Pressures

Femoral vein

(Pts. W. G., J. P., R. D.) Mean, mm, $H_{8}$

Right atrium

Right ventricle

(Pts. W. G., J. P.)

Pulmonary artery

(Pts. W. G., J. P.)

Systolic, $\mathrm{mm} . \mathrm{Hg}$

End diastolic, $m m . H_{g}$

Systolic, mm. $\mathrm{Hg}$

Diastolic, mm. $\mathrm{Hg}_{\mathrm{g}}$

Mean, $m m . H_{g}$

Femoral artery

Systolic, $m m . H g$ Diastolic, $\mathbf{m m}$. $\mathrm{H}_{\mathrm{g}}$ Mean, mm. $\mathrm{Hg}$

Mean, $\mathrm{mm}$. $\mathrm{Hg}$

\begin{tabular}{l|l|l|l|l|l|l|l|l|r|r|r}
3 & & 17.8 & 17.3 & 16.5 & 14.8 & 10.3 & 10.3 & 8.3 & 8.2 & 8 & 5.3 \\
3 & 21 & 19 & 20 & 16 & 14 & 12 & 12 & 10 & 12 & 10 \\
2 & 38 & 42 & 40 & 38 & 40 & 40 & 38 & 35 & 37 & 41 \\
2 & 15 & 19 & 15 & 16 & 14 & 12 & 12 & 8 & 7 & 7 \\
2 & 39 & 42 & 35 & 42 & 38 & 39 & 38 & 35 & 42 & 42 \\
2 & 26 & 29 & 27 & 29 & 24 & 25 & 26 & 23 & 20 & 20 \\
2 & 32 & 32 & 32 & 35 & 29 & 28 & 30 & 28 & 28 & 30 \\
5 & 155 & 150 & 153 & 164 & 165 & 172 & 176 & 180 & 179 & 175 \\
5 & 98 & 94 & 97 & 103 & 101 & 98 & 93 & 94 & 91 & 92 \\
5 & 118 & 113 & 114 & 122 & 125 & 124 & 118 & 122 & 118 & 119 \\
\hline
\end{tabular}

Cardiovascular Dynamics

Cardiac output, liters/min.

Systemic vascular resistance, dynes sec. $\mathrm{cm} .^{-\mathrm{s}}$

\begin{tabular}{l|r|r|r|r|r|r|r|r|r|r|r|r}
5 & 5.4 & 3.3 & 3.1 & 3.4 & 4.2 & 4.4 & 4.5 & 4.6 & 4.0 & 二 \\
5 & 2,880 & 3,020 & 3,030 & 3,160 & 2,690 & 2,410 & 2,270 & 2,280 & 2,730 &
\end{tabular}

Blood Volumes

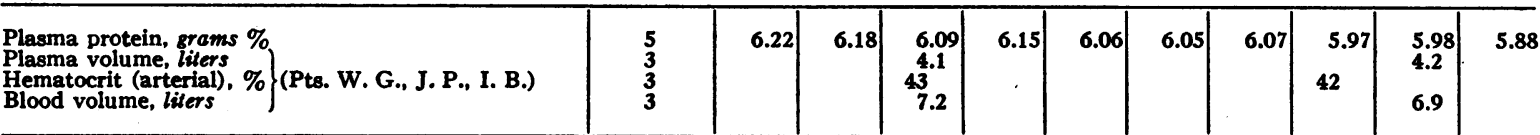

Renal Dynamics

Glomerular filtration rate, ml./min.

Renal plasma flow, wl./min.

Filtration fraction, \%

Renal blood flow, $\mathrm{ml}$./min.

Renal vascular resistance, dynes sec. $\mathrm{cm} .^{-b}$

Renal fraction,

\begin{tabular}{|c|c|c|c|c|c|c|c|c|c|c|c|}
\hline Renal fraction, \% & 5 & 9.1 & 9.2 & 9.7 & 9.5 & 7.9 & 7.3 & 8.3 & 7.2 & 9.3 & $20,-$ \\
\hline \multicolumn{12}{|c|}{ Urine Excretions } \\
\hline 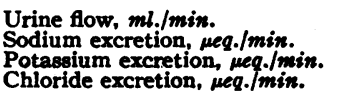 & $\begin{array}{l}5 \\
5 \\
5 \\
5\end{array}$ & $\begin{array}{l}1.3 \\
34 \\
34 \\
27\end{array}$ & $\begin{array}{l}31.2 \\
31 \\
26\end{array}$ & $\begin{array}{l}1.1 \\
25 \\
30 \\
19\end{array}$ & $\begin{array}{l}1.2 \\
36 \\
42 \\
29\end{array}$ & $\begin{array}{c}2.0 \\
98 \\
52 \\
107\end{array}$ & $\begin{array}{l}2.7 \\
128 \\
63 \\
136\end{array}$ & $\begin{array}{l}3.2 \\
156 \\
69 \\
146\end{array}$ & $\begin{array}{l}3.2 \\
154 \\
60 \\
146\end{array}$ & $\begin{array}{l}3.3 \\
186 \\
67 \\
192\end{array}$ & $\begin{array}{l}4.3 \\
23.3 \\
73 \\
267\end{array}$ \\
\hline
\end{tabular}

* Renal, urinary and electrolyte data are averages for the periods; cardiovascular and respiratory data are for midpoints of the periods. The concentrations of sodium, potassium and chloride in blood did not change throughout the 10 periods. In calculating systemic and renal vascular resistances the pressure gradient was taken as mean femoral artery pressure minus mean right atrial pressure or femoral venous pressure.

† Digoxin $1.0 \mathrm{mg}$. to $1.5 \mathrm{mg}$. given during first 10 minutes of period 4 . 


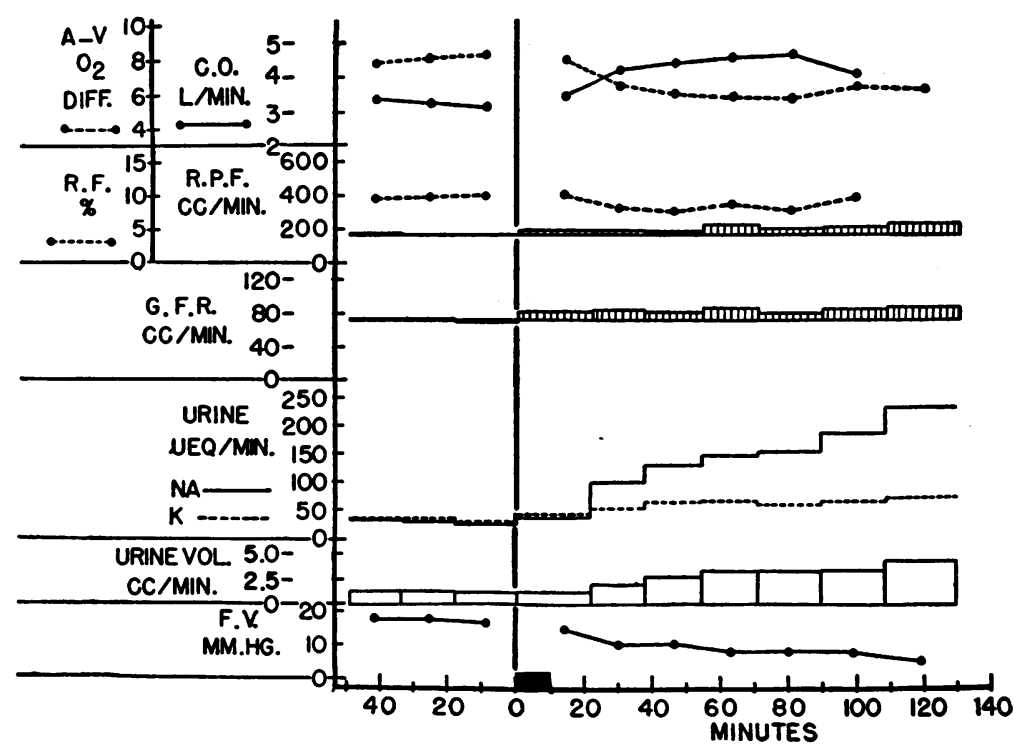

Fig. 1. Cardiovascular, Renal and Electrolyte Effects of Digoxin Administered. Intravenously to Patients with Congestive Heart FAILURE

The averaged data for the five patients are presented.

This chart and subsequent charts are similarly plotted: On the abscissa is time in minutes. The black box immediately above the abscissa indicates the time and duration of the digoxin injection. On the ordinate are plotted, in order, from below upward, femoral venous pressure or right atrial pressure in $\mathrm{mm} . \mathrm{Hg}$; urine flow in $\mathrm{ml} . / \mathrm{min}$.; urinary sodium (solid line) and potassium (dotted line) excretions in $\mu$ eq./min.; glomerular filtration rate and renal plasma flow in $\mathrm{ml} . / \mathrm{min}$., plotted for each period, including control periods, about the mean of the three control periods as the reference line; renal fraction (dotted line) in per cent of cardiac output; cardiac output (solid line) in liters/min. and A-V oxygen difference (dotted line) in vols. $\%$.

major effects of the drug were all present and changing progressively (Table I).

There were no apparent changes in plasma volume, blood volume or hematocrit. Respiratory rate, ventilation volume and oxygen consumption did not change, or fell slightly in the patients who initially manifested the greatest respiratory distress. The electrocardiogram either remained unchanged or showed minimal lowering of $\mathrm{T}$ waves.

Arterial oxygen content, and saturation, consistently decreased sharply in the first and second periods after digoxin and thereafter fell more slowly and progressively. This decrease, especially the first sharp fall, was not attributed to the repeated blood sampling for the hematocrit remained essentially unchanged.

Although initially (period 4) the systolic and diastolic arterial pressures both increased, the subsequent change (beginning in period 5) was a progressive widening of the pulse pressure, which resulted from a considerable rise in systolic pressure and a small fall in diastolic pressure.

In two patients, ventricular premature contractions began to appear approximately one hour after the injection of digoxin and increased in frequency, until two hours after injection one patient had a sustained idioventricular rhythm and the other had five or six short runs ( 4 to 6 beats) of ventricular tachycardia per minute. In both patients the arterial pressures were maintained and the right atrial pressures remained at their lowered levels. However, cardiac output fell and $A-V$ oxygen difference increased (Figures 4 and 6 ). These changes were sufficiently marked to influence adversely the average values for these functions (period 9, Table I) even though improved values were sustained in the other patients.

Renal hemodynamic effects. The averaged 


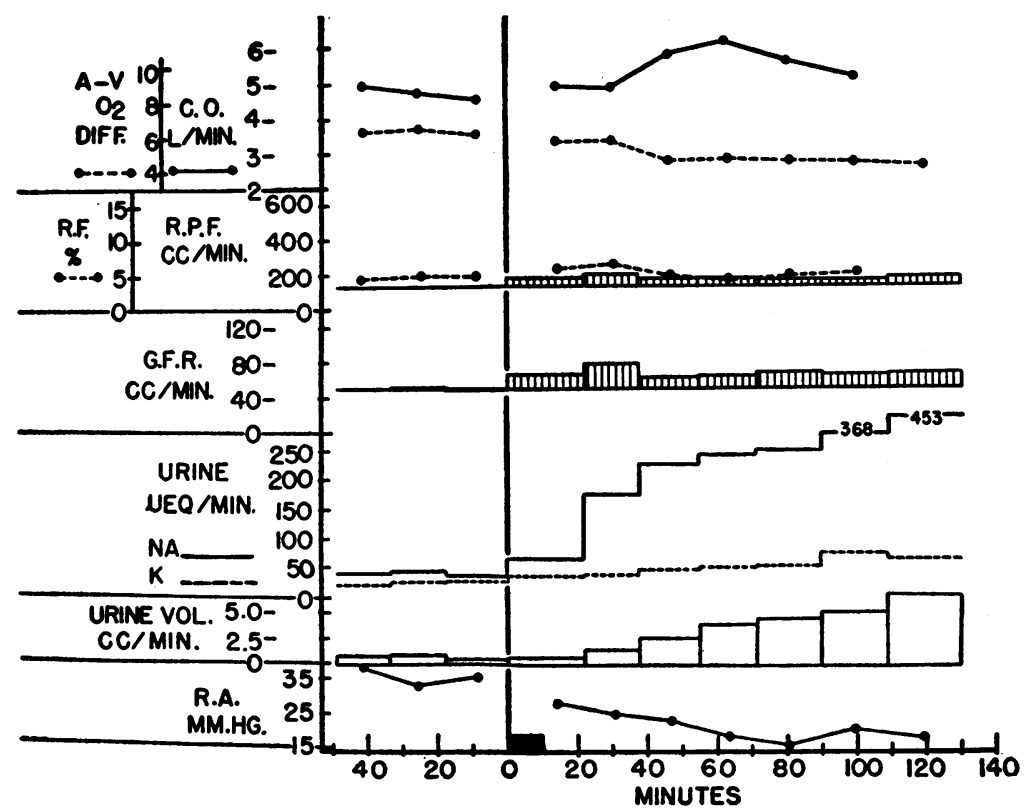

Fig. 2. Cardiovascular, Renal and Electrolyte Effects of 1.5 mg. Digoxin Administered Intravenously to B. A.

White female, 60 years, hypertensive and arteriosclerotic heart disease, enlarged heart, auricular fibrillation with ventricular rate $122 / \mathrm{min}$., paroxysmal nocturnal dyspnea, peripheral edema $3+$, class IV E. (For details of charting see legend of Figure 1.)

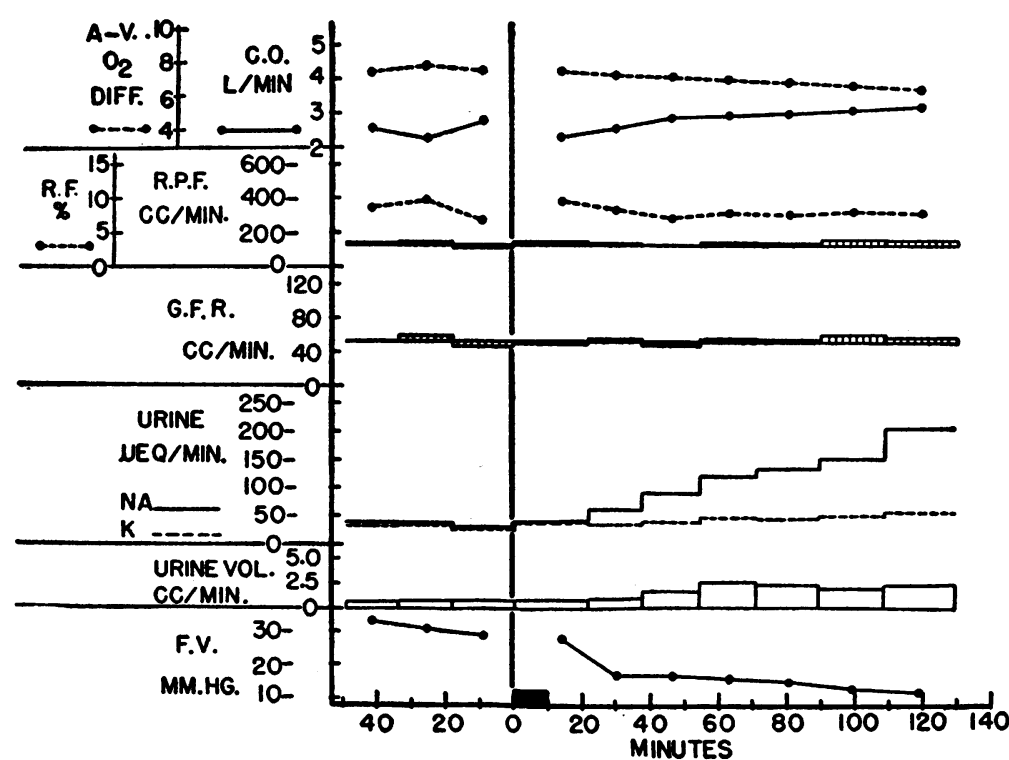

Fig. 3. Cardiovascular, Renal and Electrolyte Effects of 1.3 mg. Digoxin AdMinistered IntravenousLy to W. G.

White male, 70 years, healed pneumococcal endocarditis and arteriosclerotic heart disease, enlarged heart, auricular fibrillation with ventricular rate 78/ min., $2+$ peripheral edema, class III D. (For details of charting see legend of Figure 1.) 


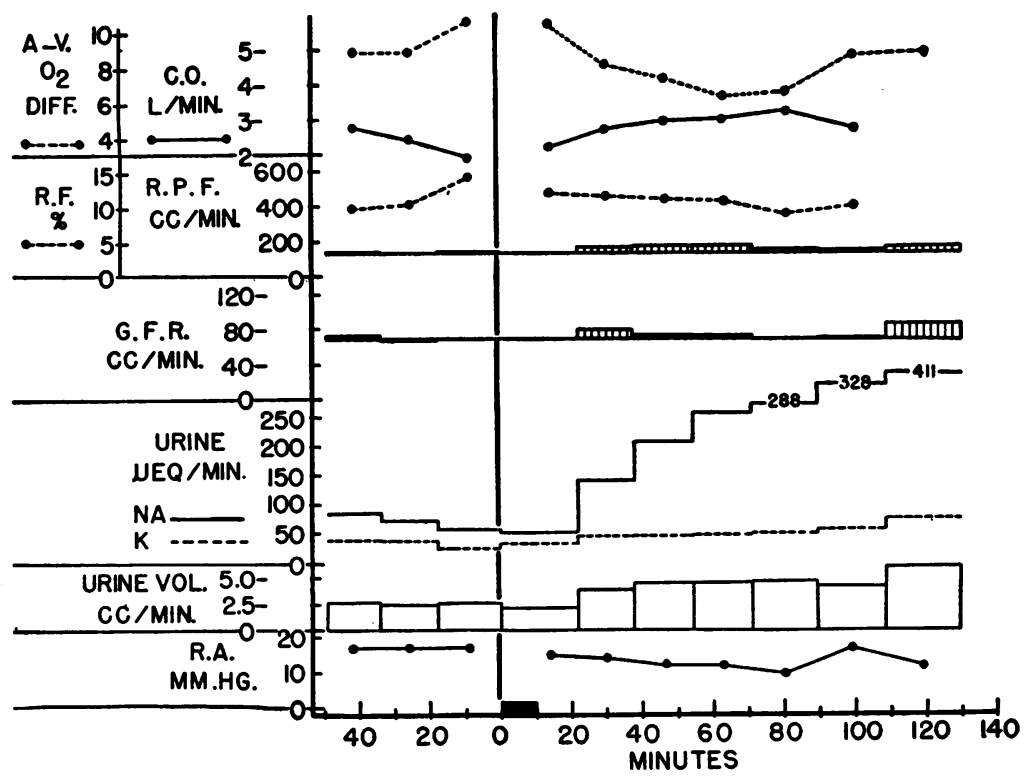

Fig. 4. Cardiovascular, Renal and Electrolyte Effects of 1.0 mg. Digoxin. Administered Intravenously to I. B.

Negro female, 52 years, rheumatic heart disease, enlarged heart, mitral stenosis and insufficiency, auricular fibrillation with ventricular rate $126 / \mathrm{min}$., $4+$ peripheral edema, class IV E. Five days previously $0.5 \mathrm{mg}$. digoxin was given intravenously, none since. After period 6, ventricular premature contractions appeared and increased to five or six runs of 4 to 6 consecutive idioventricular beats/min. (For details of charting see legend of Figure 1.)

data for the five patients show small increases in renal plasma flow, renal blood flow and glomerular filtration rate (Table I, Figure 1). Thus, one and a half to two hours after digoxin the averaged renal plasma flow had increased by $51 \mathrm{ml} . / \mathrm{min}$., from 157 to $208 \mathrm{ml} . / \mathrm{min}$., the averaged renal blood flow had increased by $75 \mathrm{ml} . / \mathrm{min}$., from 280 to $355 \mathrm{ml} . / \mathrm{min}$., and the averaged glomerular filtration rate had risen by $15 \mathrm{ml} . / \mathrm{min}$., from 69 to $84 \mathrm{ml} . / \mathrm{min}^{4}$ There was considerable variation in the response from subject to subject. Usually the onset of the changes occurred at some time within 45 minutes after the injection of digoxin (Figures 2, 4, 5, 6). After the initial rise, renal plasma flow increased progressively to a small extent in some subjects and not at all in others, while glomerular filtration rate was usually sustained at the new level without subsequent appreciable change. The renal hemodynamic response was rated as a definite and sustained im-

4 The initial values are the averages of the three control periods; the final values are the averages of periods 9 and 10. provement in two patients (Figures 2 and 5) ; improvement with considerable variation from period to period in one patient (Figure 6), equivocal improvement in one patient (Figure 4); and in one patient no improvement until a slight increase in periods 9 and 10 (Figure 3). However, after digoxin was given, no patient showed a definite or sustained reduction in renal plasma flow or filtration rate below the average values of his three control periods.

Filtration fraction changed little. The averaged value before digoxin was $45 \%$, the final value $41 \%$. Three patients showed slight falls, the other two patients only equivocal changes.

Unlike the progressive decrease in systemic vascular resistance, renal vascular resistance did not fall. On the contrary, three subjects showed slight increases in renal resistance during the first three periods after digoxin and then a return to the initial levels; the other two subjects showed essentially no changes. Probably associated with this behavior in renal resistance was the tendency for the already low renal fraction (per cent of 


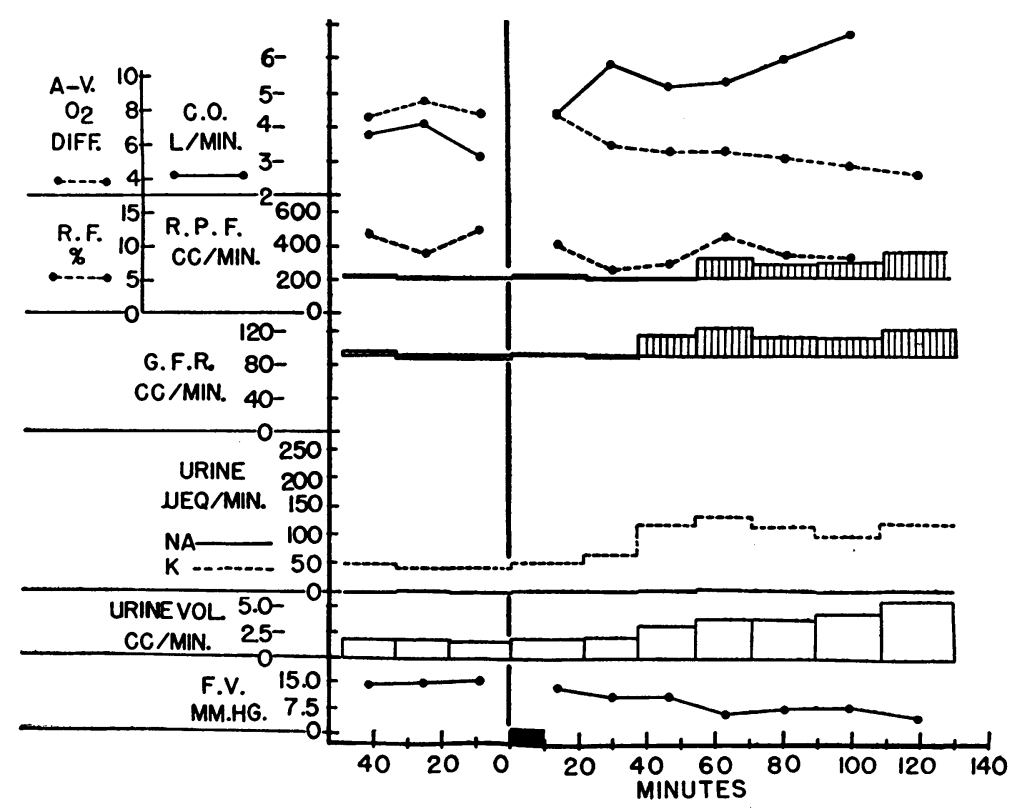

Fig. 5. Cardiovascular, Renal and Electrolyte Effects of $1.0 \mathrm{mg}$. Digoxin Administered Intravenously to J. P.

White male, 53 years, unknown type and arteriosclerotic heart disease, enlarged heart, auricular fibrillation with ventricular rate $148 / \mathrm{min} ., 4+$ edema, moderate dyspnea, class IV E. Serum sodium $113 \mathrm{mEq} . / \mathrm{L}$. Twelve hours previously $0.5 \mathrm{mg}$. of digoxin had been given intravenously. (For details of charting see legend of Figure 1.)

cardiac output perfusing the kidney) to decrease further as the cardiac output increased (Table I, Figure 1). Although the averaged renal fraction fell from $9.5 \%$ to $7.5 \%$ during the drug's action, individual responses varied widely. In some patients renal fraction decreased, in others it remained unchanged, but in no patient did renal fraction increase. A further dissociation between renal blood flow and cardiac output was noted in the patients whose cardiac outputs fell as ventricular arrhythmia developed. Renal blood flow was maintained and, as a result, the renal fraction increased as cardiac output decreased (Figure 6).

Urine volume and electrolyte excretion. Digoxin produced a prompt and progressive increase in urine volume and in the rate of excretion of electrolytes (Table I, Figure 1). Occasionally the first urine collected after digoxin (20 minutes after start of injection) showed these changes (Figure 2) but in all instances the second urine specimens (from the 20th to 35 th minute after start of injection) showed increases in volume and in the quantity of sodium, chloride and potassium excreted (Figures 2-6). Thereafter, urine volume and electrolyte excretions increased progressively, until one and a half to two hours after injection the averaged urine volume had increased threefold, averaged sodium excretion sevenfold, averaged chloride excretion tenfold and averaged potassium excretion twofold. During these increased excretions, the concentrations of the three electrolytes in the blood remained unchanged.

Generally water and electrolyte excretions increased concomitantly (Figures 2-4). However, in one subject the increased electrolyte excretion was accompanied by only a minimal change in water excretion (Figure 6). Increased water excretion without increased electrolyte excretion was not observed. In a markedly edematous patient with hyponatremia (serum sodium 113 $\mathrm{mEq} . / \mathrm{L}$.) the increase in urine volume was accompanied by only a slight rise in the very low output of sodium in the urine. However, the diuresis was accompanied by the increased excretion of potassium and chloride (Figure 5).

An additional patient, in moderately severe 
congestive heart failure, also received $1.0 \mathrm{mg}$. digoxin intravenously. He was considered to have arteriosclerotic heart disease and in addition, chronic glomerulonephritis (GFR $42 \mathrm{ml} . / \mathrm{min}$., RPF $235 \mathrm{ml} . / \mathrm{min} ., \mathrm{FF} \mathrm{18 \% )}$ and anemia. Approximately 45 minutes after receiving the drug he developed pulmonary edema and required morphine sulfate $(8 \mathrm{mg}$.) intravenously to control the respiratory distress and permit completion of the observations. No changes in cardiovascular or renal hemodynamics or in urine volume and electrolyte excretion occurred in this patient and his data have not been averaged with the five patients who were benefited by digoxin. This absence of effect remains unexplained but, perhaps, congestive failure accompanying glomerulonephritis does not respond in the same manner as the failure due to heart disease alone.

Control observations. The cardiovascular, renal, urinary and electrolyte changes produced by digoxin in congestive heart failure did not occur in three patients who underwent the full test pro- cedures and served as controls: $a$ ) a patient with essential hypertension, without congestive heart failure, who received $1.5 \mathrm{mg}$. digoxin intravenously, $b$ ) a normotensive subject without congestive heart failure who received $1.3 \mathrm{mg}$. digoxin intravenously and $c$ ) a patient with arteriosclerotic heart disease and severe congestive heart failure who received no medication. In the last patient renal plasma flow, glomerular filtration rate, electrolyte excretions and urine flow decreased as the observation period continued, while cardiac output and right atrial pressure remained unchanged (Figure 7).

\section{DISCUSSION}

The patients studied were few but the data indicate definite patterns of effect for each of the several functions studied and show consistent similarities and differences between the responses of the several functions. Furthermore, generalizations based on these data appear tenable, for the results of the present integrated observations are

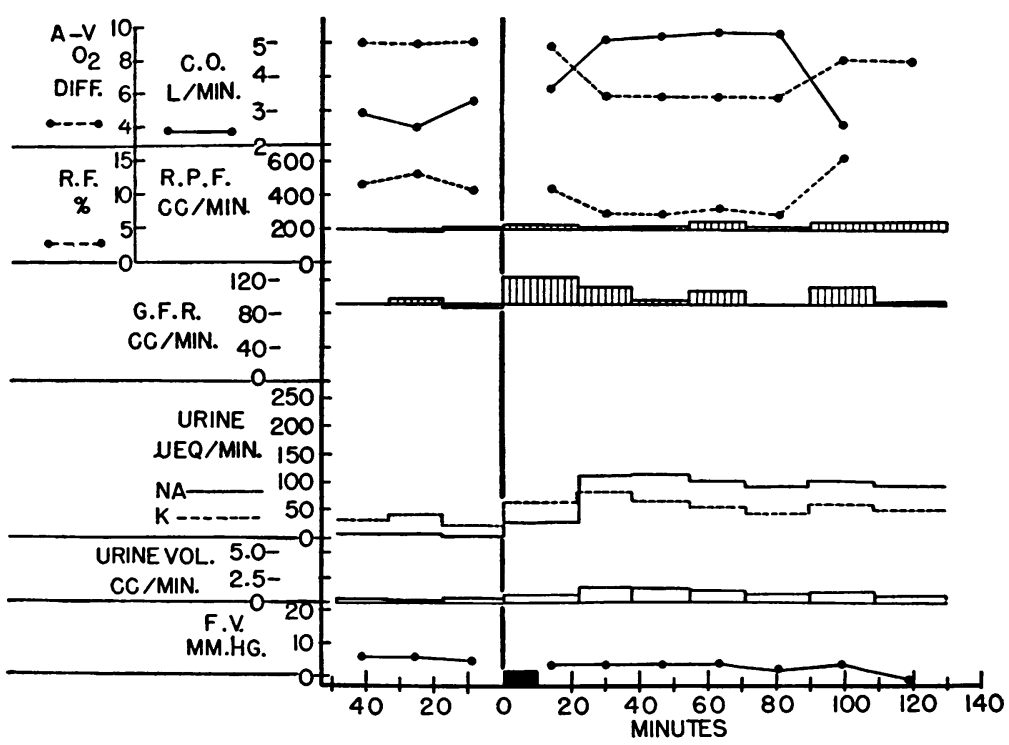

Fig. 6. Cardiovascular, Renal and Electrolyte Effects of 1.2 mg. Digoxin Administered Intravenously to R. D.

White male, 68 years, hypertensive and arteriosclerotic heart disease, enlarged heart, auricular fibrillation with ventricular rate $110 / \mathrm{min}$., marked respiratory distress and Cheyne-Stokes respiration, $1+$ peripheral edema, class IV E. In period 6, ventricular premature contractions appeared and increased in frequency until in periods 9 and 10 there were several runs of 10 to 30 consecutive idioventricular beats/min. After period 10 sustained idioventricular rhythm developed which was restored to sinus rhythm by procaine intravenously. (For details of charting see legend of Figure 1.) 


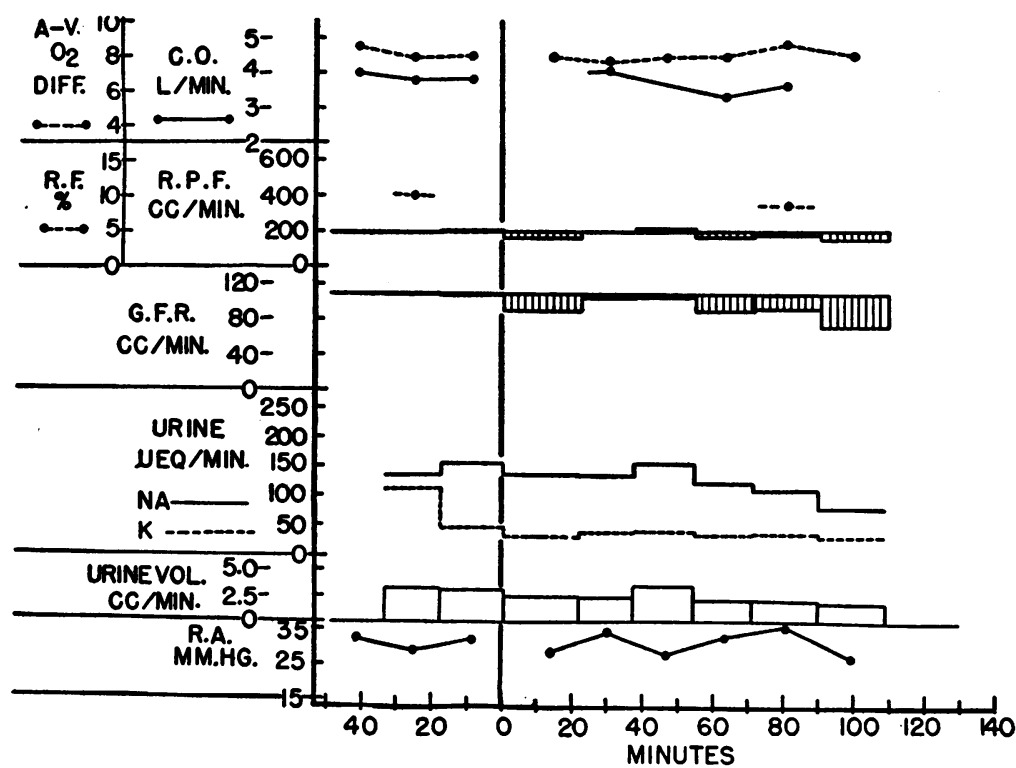

Fig. 7. Cardiovascular, Renal and Electrolyte Effects of the Full Test Procedure Alone. No Medication Given.

F. W., negro male, 64 years, unknown type and arteriosclerotic heart disease, enlarged heart, regular sinus rhythm with ventricular rate $102 / \mathrm{min}$., ventricular and atrial premature contractions, moderate dyspnea, $4+$ peripheral edema, class IV E. (For details of charting see legend of Figure 1.)

supported by data obtained in larger series of patients, in whom either cardiovascular hemodynamic observations alone (1-5) or renal hemodynamic and urinary studies alone (9) were carried out.

The cardiovascular hemodynamic changes produced by digoxin were similar to those already reported (1-5). To these reports the present study adds more detailed and sequential observations.

The data do not indicate, as had been hoped, the primary site of action of digoxin, whether on the myocardium to increase stroke volume and cardiac output primarily, or on a vascular bed to relax its tonus, reduce thereby cardiac overstretch and increase cardiac output secondarily. The data suggest that peripheral venous and right atrial pressures fell before cardiac output increased. Thus, the first determinations after digoxin (five minutes after the finish of injection) showed an averaged decrease of $14 \%$ in femoral venous pressure, with a fall in pressure in all patients, and an averaged decrease of $25 \%$ in right atrial pressure, with pressure falls in four of the five subjects; in contrast, cardiac output showed an averaged increase of only $6 \%$ and only one subject showed an une- quivocal rise. The next measurements, 15 minutes later, showed such marked changes in femoral venous pressure, right atrial pressure and cardiac output in practically all patients that resolution of primary from secondary effects was not possible. Since per cent changes from control values need not necessarily correlate with the physiological effectiveness of a change and since the effects were in such close relationship to each other, the present data are considered not to determine the primary effect of digoxin.

In general, renal hemodynamics appeared to improve slightly following digoxin. Since the changes in renal hemodynamics were small in absolute values and close to the error of the methods of measurement, the question arises whether the changes were real. The following reasons suggest that these small increases may indeed be considered to be real. For each patient, the increases were of greater magnitude than the variations from period to period during the three control periods. When the changes occurred, they were almost always in the same direction, increases above the average of the values for the three control periods; decreases were encountered rarely and then 
were small and not sustained. Finally, even though conclusions based on statistical analyses of such small samples may be open to question, nonetheless, an analysis of the values for periods 1,2 , and 3 with the values for periods 9 and 10 gives for GFR a $t$ value of $3.61, \mathrm{P}=0.03$, and for $\mathrm{RPF}$ a $t$ value of $2.67, \mathrm{P}=0.06$, values which are at the borderline of statistical significance. The conclusion remains that in general renal hemodynamics improved slightly but in individual patients measurable changes were at times absent.

The averaged data for all of the subjects show that the maximal percentile changes in renal hemodynamic functions (glomerular filtration rate $+20 \%$, renal blood flow $+27 \%$, renal plasma flow $+32 \%)^{4}$ approached the maximal percentile changes in cardiovascular hemodynamics (cardiac output $+41 \%$, A-V oxygen difference $-29 \%$, right atrial pressure $-50 \%) .^{5}$ However, such an analysis obscures important differences between the changes in these two categories of functions. Thus, the renal effects were quite small in absolute values and in no instance were renal hemodynamics returned to normal. In contrast, the cardiovascular effects were sizable and definite and several of the cardiovascular functions, particularly cardiac output, A-V oxygen difference and right atrial pressure, were often returned to normal.

Rapid phlebotomy has been shown to improve cardiovascular dynamics in congestive heart failure (2) and to decrease glomerular filtration rate and electrolyte excretion in normal subjects (18). The repeated blood sampling in the present study caused a total blood loss of $300 \mathrm{ml}$. to $400 \mathrm{ml}$. and the effect of this blood loss alone on the functions studied must be considered. At least in one control subject (Figure 7 ), the relatively slow blood loss of the repeated blood sampling did not improve cardiovascular hemodynamics, while glomerular filtration rate and water and electrolyte excretions were decreased by amounts similar to those observed in normal subjects who were bled (18). Since these changes were strikingly different, some of them in the opposite direction, from the effects in the digoxin-treated patients, it seems unlikely that the blood loss alone played a significant part in the effects noted after digoxin.

The changes in renal plasma flow and glomeru-

5 See footnote on page 1255. lar filtration rate appeared to be associated with the improvement in the general circulation, but they were less consistent, rather slower in onset and less progressive than the general cardiovascular effects. Moreover, in some instances there were no changes in one, or both, of these renal hemodynamic functions in the presence of considerable cardiovascular changes (Figure 3 ). The differences in the general circulatory and renal circulatory effects of digoxin are further indicated by the tendency for renal vascular resistance to increase, or remain unchanged, as the systemic vascular resistance decreased, and by the fall in renal fraction as the cardiac output rose.

One of the most striking and consistent effects of digoxin was the prompt and pronounced increase in urine flow and in the rate of excretion of electrolytes. There appeared to be no consistent relationship between these urinary changes and the changes in glomerular filtration rate and renal plasma flow. In general, water and electrolyte excretions increased coincidently with a slight improvement in these renal functions (Figures 1 and 2) but the diureses were not necessarily dependent on such improvement (Figure 3 ). In some subjects water and electrolyte diureses occurred in the virtual absence of changes in renal plasma flow or glomerular filtration rate, or both (Figure 3 ); in others the diureses preceded an improvement in either one or both of these renal hemodynamic functions (Figure 5). Furthermore, the increases in water and electrolyte excretions were marked and progressive, whereas the absolute improvement in GFR and RPF was relatively small and not progressive. Similar dissociations following digoxin have been reported in a larger group of subjects (9) and in four of the 12 patients with congestive heart failure therein studied, water and electrolyte diureses occurred in the absence of changes in glomerular filtration or renal plasma flow (9).

There was a closer relationship between the urinary changes and the general cardiovascular effects. Thus, the increases in water and electrolyte excretions coincided with the increase in cardiac output and the concomitant development of the peripheral circulatory changes of increased arterial pulse pressure and decreased systemic venous pressure. It seems more reasonable that 
the diuresis should be related to some renal change, perhaps of a circulatory nature and related to cardiac output, than to so general a cardiovascular function as cardiac output itself. This suggestion receives support from the observations in the two subjects who developed ventricular arrhythmia. Although the cardiac output fell, the water and electrolyte excretions remained elevated and, perhaps significantly, the peripheral circulatory changes which had developed remained at their new levels, the arterial pulse pressure wide and the systemic venous pressure low. It is probable that similar pressure changes occurred in the renal circulation and to these changes the water and electrolyte diureses seemed closely related.

The close relationship between the probable arterial and venous pressure changes in the kidney and the increased water and electrolyte excretions does not prove a causal relationship. The relationship may be a concomitant one and the diureses may be secondary to some other primary effect, not herein studied. Factors which must be considered and which require evaluation include a direct effect of digoxin on the renal tubule cell (9) and the influence of some humoral factor, pituitary or adrenal in origin, activated or eliminated by the changing cardiovascular hemodynamics.

In short, digoxin administered intravenously to patients with congestive heart failure produces a prompt and marked improvement in general cardiovascular hemodynamics, a slower, somewhat inconsistent but suggestive improvement in renal blood flow and glomerular filtration rate, and a prompt and marked water and electrolyte diuresis. The diureses seem less consistently related to changes in renal blood flow and glomerular filtration than to changes in cardiovascular hemodynamics.

\section{SUMMARY}

1. Serial determinations were made of the cardiovascular, renal and urinary functions of five patients with congestive heart failure during the two hours following the intravenous administration of single therapeutic doses of digoxin.

2. The cardiovascular hemodynamic effects appeared within 15 to 20 minutes, improved markedly in the first 30 minutes, progressed more slowly thereafter and consisted of the following: ventricular slowing, increased cardiac output, increased oxygen content of mixed venous blood, de- creased A-V oxygen difference, decreased peripheral venous and right atrial pressures, decreased right ventricular end diastolic pressure, decreased pulmonary diastolic pressure and widened femoral arterial pressure. Blood volume did not change.

3. Because the cardiovascular functions changed rapidly and concomitantly it was not possible to resolve cause from effect and determine the site of primary action of digoxin.

4. Unlike the uniform changes in cardiovascular dynamics, the changes in renal plasma flow and glomerular filtration rate were less consistent, smaller in absolute values and slower in onset and progression. In general, they were slightly increased one and a half to two hours after digoxin; filtration fraction was slightly lower.

5. In contrast to the inconsistent changes in GFR and RPF, urine flow and the rate of excretion of sodium and chloride, and to a lesser extent of potassium, increased promptly, within $30 \mathrm{~min}$ utes of digoxin injection, and continued to increase markedly and progressively.

6. Although water and electrolyte excretion generally increased concomitantly with the slight improvement in filtration rate and renal plasma flow, the diureses were not consistently, nor necessarily, related to improvement in these renal hemodynamic functions.

7. The increased water and electrolyte excretions appeared closely associated with changes in renal vascular pressures, as represented by increased arterial pulse pressure and decreased systemic venous pressure.

\section{ACKNOWLEDGMENTS}

The authors wish to thank Mr. William H. Becker, Mr. William Ponman, Miss Dorothy De Lorenzo and Miss Shirley Elliot for the careful analysis of the many specimens and Miss Bernice Aparo and Miss Dorothy Connolly for technical assistance with the observations.

\section{REFERENCES}

1. McMichael, J., and Sharpey-Schafer, E. P., The action of intravenous digoxin in man. Quart. J. Med., 1944, 13, 123.

2. Howarth, S., McMichael, J., and Sharpey-Schafer, E. P., Effects of venesection in low output heart failure. Clin. Sc., 1946, 6, 41.

3. Howarth, S., McMichael, J., and Sharpey-Schafer, E. P., Effects of oxygen, venesection and digitalis in chronic heart failure from disease of the lungs. Clin. Sc., 1947, 6, 187. 
4. Harvey, R. M., Ferrer, M. I., Cathcart, R. T., Richards, D. W., Jr., and Cournand, A., Some effects of digoxin upon the heart and circulation in man. Digoxin in left ventricular failure. Am. J. Med., 1949, 7, 439.

5. Ferrer, M. I., Harvey, R. M., Cathcart, R. T., Webster, C. A., Richards, D. W., Jr., and Cournand, A., Some effects of digoxin upon the heart and circulation in man. Digoxin in chronic cor pulmonale. Circulation, 1950, 1, 161.

6. Bloomfield, R. A., Rapoport, B., Milnor, J. P., Long, W. K., Mebane, J. G., and Ellis, L. B., The effects of the cardiac glycosides upon the dynamics of the circulation in congestive heart failure. I. Ouabain. J. Clin. Invest., 1948, 27, 588.

7. Stead, E. A., Jr., Warren, J. V., and Brannon, E. S., Effect of lanatoside $C$ on the circulation of patients with congestive failure. A study using catheterization of the right side of the heart. Arch. Int. Med., 1948, 81, 282.

8. Eichna, L. W., and Taube, H., The effect of intravenously administered digoxin and ouabain on the systemic venous pressure of patients with congestive heart failure. Am. Heart J., 1944, 27, 641.

9. Farber, S. J., Alexander, J. D., Pellegrino, E. D., and Earle, D. P., The effect of intravenously administered digoxin on water and electrolyte excretions and on renal functions. Circulation, 1951, 4, 378.

10. Cournand, A., and Ranges, H. A., Catheterization of the right auricle in man. Proc. Soc. Exper. Biol. \& Med., 1941, 46, 462.
11. Van Slyke, D. D., and Neill, J. M., The determination of gases in blood and other solutions by vacuum extraction and manometric measurement. I. J. Biol. Chem., 1924, 61, 523.

12. Phillips, R. A., Van Slyke, D. D., Dole, V. P., Emerson, K., Jr., Hamilton, P. B., and Archibald, R. M., Copper sulfate method for measuring specific gravities of whole blood and plasma. Monograph, Josiah Macy, Jr. Foundation, Feb. 1945.

13. Gibson, J. G., 2nd, and Evans, W. A., Jr., Clinical studies of the blood volume. I. Clinical application of a method employing the azo dye "Evans blue" and the spectrophotometer. J. Clin. Invest., 1937, 16, 301.

14. Harrison, H. E., A modification of the diphenylamine method for the determination of inulin. Proc. Soc. Exper. Biol. \& Med., 1942, 49, 111.

15. Alving, A. S., Rubin, J., and Miller, B. F., A direct colorimetric method for the determination of inulin in blood and urine. J. Biol. Chem., 1939, 127, 609.

16. Bratton, A. C., and Marshall, E. K., Jr., A new coupling component for sulfanilamide determination. J. Biol. Chem., 1939, 128, 537.

17. Jeffrey, W. H., Note on the Volhard-Harvey method for estimation of chlorides in urine. J. Lab. \& Clin. Med., 1927-28, 13, 687.

18. Lombardo, T. A., Eisenberg, S., Oliver, B. B., Viar, W. N., Eddleman, E. E., Jr., and Harrison, T. R., Effects of bleeding on electrolyte excretion and on glomerular filtration. Circulation, 1951, 3, 260. 